\title{
Quantitative Structure-cytotoxicity Relationship of 3-Benzylidenechromanones
}

\author{
YOSHIHIRO UESAWA ${ }^{1}$, HIROSHI SAKAGAMI ${ }^{2}$, HAJIME KAGAYA ${ }^{1}$, \\ MARIMO YAMASHITA ${ }^{3}$, KOICHI TAKAO $^{3}$ and YOSHIAKI SUGITA ${ }^{3}$ \\ ${ }^{1}$ Department of Clinical Pharmaceutics, Meiji Pharmaceutical University, Kiyose, Japan; \\ ${ }^{2}$ Division of Pharmacology, Meikai University School of Dentistry, Sakado, Japan; \\ ${ }^{3}$ Faculty of Pharmaceutical Sciences, Josai University, Sakado, Japan
}

\begin{abstract}
Aim: Sixteen 3-benzylidenechromanones were subjected to quantitative structure-activity relationship (QSAR) analysis based on their cytotoxicity and tumor-specificity, in order to examine their new biological activities. Materials and Methods: Cytotoxicity against two human oral squamous cell carcinoma cell lines, two mesenchymal and two epithelial normal oral cells, was determined by the 3-(4,5-dimethylthiazol2-yl)-2,5-diphenyltetrazolium bromide method. Tumor-specificity (TS) was evaluated by the ratio of the mean $C_{50}(50 \%$ cytotoxic concentration) against normal cells to that against tumor cell lines. Physicochemical, structural and quantumchemical parameters were calculated based on the conformations optimized by the LowModeMD method. Results. 3-Benzylidenechromanone derivatives that have a methoxy group at 7-position of the chromanone ring and hydroxyl or methoxy group at 4'-position of benzene ring showed relatively higher TS values, exceeding those of doxorubicin (DXR) and 5-fluorouracil (5-FU). Since these anticancer drugs were highly cytotoxic to normal keratinocytes, QSAR analysis was performed with oral carcinoma and mesenchymal normal cells. Tumor-specificity was well correlated with 3D-MoRSE descriptors (that relate to three dimensional shapes) and Edge adjacency indices (that relate to two dimensional shapes and polarization). Introduction of hydroxyl group at 3'-position of benzene ring significantly elevated the tumor-specificity. Conclusion: Molecular shape, size and polarization are useful markers for the evaluation of tumorspecificity of 3-benzylidenechromanone derivatives.
\end{abstract}

This article is freely accessible online.

Correspondence to: Yoshihiro Uesawa, Department of Clinical Pharmaceutics, Meiji Pharmaceutical University, 2-522-1 Noshio, Kiyose, Tokyo 204-858, Japan. Tel/Fax: +81 424958892, e-mail: uesawa@my-pharm.ac.jp

Key Words: 3-benzylidenechromanones, QSAR analysis, cytotoxicity, tumor selectivity, oral carcinoma, mesenchymal and epithelial normal oral cells.
(3E)-3-Benzylidene-2,3-dihydro-4H-1-benzopyran-4-ones (3benzylidene-4-chromanones) constitute a small class of natural products primarily isolated from Hyacinthaceae and Caesalpinioideae (1-5). Several natural and synthetic 3benzylidene-4-chromanones are related structurally to flavonoids and found to possess various biological properties, such as antioxidant, antifungal, antiviral, anti-mutagenic, antiproliferative, anti-allergic, antihistaminic, anti-inflammatory and monoamine oxidase inhibitory activity (6-17). However, no systematically evaluated data are available on the cytotoxic activity of 3-benzylidene-4-chromanone derivatives against both malignant and non-malignant cells.

In order to further explore novel biological activities of 3benzylidenechromanones, we recently synthesized a series of seventeen derivatives (Figure 1). In the present study, we first investigated their cytotoxicity against human oral squamous cell carcinoma (OSCC) cell lines (Ca9-22, HSC-2), human normal oral cells derived from mesenchymal tissue (gingival fibroblast, HGF; pulp cells, HPC) and epithelial tissue (oral keratinocyte, HOK; primary gingival epithelial cells, HGEP). Tumor-specificity index (TS) was calculated by dividing the mean $50 \%$ cytotoxic concentration $\left(\mathrm{CC}_{50}\right)$ against normal oral cells by that against OSCC cell lines. We have previously confirmed that the TS value thus determined reflects the antitumor potential of test samples, although normal and tumor cells are derived from different tissues (mesenchymal or epithelial) (18). We next performed the quantitative structureactivity relationship (QSAR) analysis, using the cytotoxicity data obtained with OSCC cells (Ca9-22, HSC-2) and normal oral mesenchymal cells (HGF, HPC).

\section{Materials and Methods}

Materials. The following chemicals and reagents were obtained from the indicated companies: Dulbecco's modified Eagle's medium (DMEM) from GIBCO BRL, Grand Island, NY, USA; fetal bovine serum (FBS), 3-(4,5-dimethylthiazol-2-yl)-2,5-diphenyltetrazolium bromide (MTT) and doxorubicin (DXR) from Sigma-Aldrich Inc., St. Louis, MO, USA; dimethyl sulfoxide (DMSO) from Wako Pure 
<smiles>[R]c1ccc2c(c1)OCC(=Cc1ccc([R])c([R])c1)C2=O</smiles>

\begin{tabular}{cccc}
\hline Compound & $\mathrm{R}^{1}$ & $\mathrm{R}^{2}$ & $\mathrm{R}^{3}$ \\
\hline $\mathbf{1}$ & $\mathrm{H}$ & $\mathrm{H}$ & $\mathrm{H}$ \\
$\mathbf{2}$ & $\mathrm{H}$ & $\mathrm{OH}$ & $\mathrm{H}$ \\
$\mathbf{3}$ & $\mathrm{H}$ & $\mathrm{OH}$ & $\mathrm{OH}$ \\
$\mathbf{5}$ & $\mathrm{H}$ & $\mathrm{OMe}$ & $\mathrm{H}$ \\
6 & $\mathrm{H}$ & $\mathrm{OMe}$ & $\mathrm{OMe}$ \\
$\mathbf{7}$ & $\mathrm{H}$ & $\mathrm{NMe}$ & $\mathrm{H}$ \\
8 & $\mathrm{H}$ & $\mathrm{F}$ & $\mathrm{H}$ \\
9 & $\mathrm{H}$ & $\mathrm{Cl}$ & $\mathrm{H}$ \\
10 & $\mathrm{OH}$ & $\mathrm{OH}$ & $\mathrm{H}$ \\
11 & $\mathrm{OH}$ & $\mathrm{OH}$ & $\mathrm{OH}$ \\
12 & $\mathrm{OH}$ & $\mathrm{OMe}$ & $\mathrm{H}$ \\
13 & $\mathrm{OH}$ & $\mathrm{NMe}$ & $\mathrm{H}$ \\
14 & $\mathrm{OMe}$ & $\mathrm{H}$ & $\mathrm{H}$ \\
15 & $\mathrm{OMe}$ & $\mathrm{OH}$ & $\mathrm{H}$ \\
16 & $\mathrm{OMe}$ & $\mathrm{OH}$ & $\mathrm{OH}$ \\
17 & $\mathrm{OMe}$ & $\mathrm{OMe}$ & $\mathrm{H}$ \\
\hline
\end{tabular}

Figure 1. Structure of seventeen 3-benzylidenechromanones.

Chem. Ind., Osaka, Japan; 5-fluorouracil (5-FU) from Kyowa, Tokyo, Japan. Culture plastic dishes and plates (96-well) were purchased from Becton Dickinson (Franklin Lakes, NJ, USA).

Synthesis of test compounds. (3E)-2,3-Dihydro-3-(phenylmethylene)4H-1-benzopyran-4-one [1], (3E)-2,3-dihydro-3-[(4-hydroxyphenyl) methylene]-4H-1-benzopyran-4-one [2], (3E)-2,3-dihydro-3-[(3,4dihydroxyphenyl)methylene]-4H-1-benzopyran-4-one [3], (3E)-2,3dihydro-3-[(4-methoxyphenyl)methylene]-4H-1-benzopyran-4-one [4], (3E)-2,3-dihydro-3-[(3,4-dimethoxyphenyl)methylene]-4H-1benzopyran-4-one [5], (3E)-2,3-dihydro-3-[(4-dimethylaminophenyl)methylene]-4H-1-benzopyran-4-one [6], (3E)-2,3-dihydro-3[(4-fluorophenyl)methylene]-4H-1-benzopyran-4-one [7], (3E)-3-[(4chlorophenyl)methylene]-2,3-dihydro-4H-1-benzopyran-4-one [8],
(3E)-2,3-dihydro-7-hydroxy-3-[(4-hydroxyphenyl)methylene]-4H-1benzopyran-4-one [9], (3E)-2,3-dihydro-3-[(3,4-dihydroxyphenyl)methylene]-7-hydroxy-4H-1-benzopyran-4-one [10], (3E)2,3-dihydro-7-hydroxy-3-[(4-methoxyphenyl)methylene]-4H-1benzopyran-4-one [11], (3E)-2,3-dihydro-3-[(4-dimethylaminophenyl)methylene]-7-hydroxy-4H-1-benzopyran-4-one [12], (3E)2,3-dihydro-7-methoxy-3-(phenylmethylene)-4H-1-benzopyran-4one [13], (3E)-2,3-dihydro-3-[(4-hydroxyphenyl)methylene]-7methoxy-4H-1-benzopyran-4-one [14], (3E)-2,3-dihydro-3-[(3,4dihydroxyphenyl)methylene]-7-methoxy-4H-1-benzopyran-4-one [15], (3E)-2,3-dihydro-7-methoxy-3-[(4-methoxyphenyl)methylene]4H-1-benzopyran-4-one [16] and (3E)-2,3-dihydro-3-[(4-dimethylaminophenyl)methylene]-7-methoxy-4H-1-benzopyran-4-one [17] (structures shown in Figure 1) were synthesized by base-catalyzed condensation of appropriate 4-chromanone with substituted benzaldehyde derivatives according to previous methods $(19,20)$. All compounds were dissolved in DMSO at $40 \mathrm{mM}$ and stored at $-20^{\circ} \mathrm{C}$ before use

Cell culture. HGF, HPLF and HPC cells, established from the first premolar tooth extracted from the lower jaw of a 12 -year-old girl (21), as well as OSCC cell lines (Ca9-22, HSC-2, HSC-3, HSC-4), purchased from Riken Cell Bank, Tsukuba, Japan, were cultured at $37^{\circ} \mathrm{C}$ in DMEM supplemented with $10 \%$ heat-inactivated FBS, 100 units/ml, penicillin $\mathrm{G}$ and $100 \mu \mathrm{g} / \mathrm{ml}$ streptomycin sulfate under a humidified $5 \% \mathrm{CO}_{2}$ atmosphere. $\mathrm{HOK}$ cells (purchased from COSMO BIO Co/ Ltd., Tokyo, Japan) were cultured in keratinocyte growth supplement (OKGS, Cat, No. 2652). HGEP cells (purchased from CELLnTEC Advanced Cell Systems AG, Bern, Switzerland) were grown in CnT-PR medium. Cells were then harvested by treatment with $0.25 \%$ trypsin- $0.025 \%$ EDTA-2Na in phosphate buffer without magnesium and calcium ions and either sub-cultured or used for experiments.

Assay for cytotoxic activity. Cells were inoculated at $2.5 \times 10^{3}$ cells/0.1 ml in a 96-microwell plate (Becton Dickinson Labware). After $48 \mathrm{~h}$, the medium was removed by suction with an aspirator and replaced with $0.1 \mathrm{ml}$ of fresh medium containing different concentrations of single test compounds. Control cells were treated with the same amounts of DMSO present in each diluent solution $(0.0078,0.0156,0.0312,0.0625,0.125,0.25,0.5$ and $1 \%)$ and the cell damage induced by DMSO was subtracted. Cells were incubated for $48 \mathrm{~h}$ and the relative viable cell number was then determined by the MTT method. In brief, the treated cells were incubated for another three hours in fresh culture medium containing $0.2 \mathrm{mg} / \mathrm{ml}$ MTT. Cells were then lysed with $0.1 \mathrm{ml}$ of DMSO and the absorbance at $562 \mathrm{~nm}$ of the cell lysate was determined using a microplate reader (Sunrise Rainbow RC-R; TECAN, Männedorf, Switzerland). $\mathrm{CC}_{50}$ was determined from the dose-response curve and the mean value of $\mathrm{CC}_{50}$ for each cell type was calculated from triplicate assays.

Calculation of TS. The tumor-selectivity index (TS) was calculated by the following equation: $\mathrm{TS}=$ mean $\mathrm{CC}_{50}$ against normal cells/mean $\mathrm{CC}_{50}$ against tumor cells, that is, D/B [HGF+HPC (normal mesenchymal) (D) vs. Ca9-22+HSC-2 (tumor epithelial) (B)], C/A [HGF (C) vs. Ca9-22 cells (A), derived from gingival tissue (22)] and E/B [HOK+HGEP (normal epithelial)(E) vs. Ca922+HSC-2 (tumor epithelial)(B)] (Table II). A, B, C, D and E are indicated in Table I. 
Table I. Cytotoxic activity of seventeen 3-benzylidenechromanones against human oral malignant and non-malignant cells. Each value represents the mean \pm S.D. of triplicate determinations.

\begin{tabular}{|c|c|c|c|c|c|c|c|c|c|c|c|c|c|c|c|}
\hline & \multicolumn{15}{|c|}{$\mathrm{CC}_{50}(\mu \mathrm{M})$} \\
\hline & \multirow{2}{*}{\multicolumn{5}{|c|}{$\begin{array}{l}\text { Human oral squamous } \\
\text { cell carcioma cell line }\end{array}$}} & \multicolumn{10}{|c|}{ Human oral normal cells } \\
\hline & & & & & & & & Epithelial & & & & & senchym & & \\
\hline & $\begin{array}{c}\text { (A) } \\
\text { Ca9-22 }\end{array}$ & SD & HSC-2 & SD & $\begin{array}{l}\text { (B) } \\
\text { mean }\end{array}$ & $\begin{array}{l}\text { (C) } \\
\mathrm{HGF}\end{array}$ & SD & HPC & SD & $\begin{array}{l}(\mathrm{D}) \\
\text { mean }\end{array}$ & $\mathrm{HOK}$ & SD & HGEP & SD & $\begin{array}{l}(\mathrm{E}) \\
\text { mean }\end{array}$ \\
\hline 1 & 7.6 & 3.2 & 11.2 & 0.3 & 9.4 & 75.7 & 14.0 & 77.0 & 11.5 & 76.3 & & & & & \\
\hline 2 & 24.2 & 1.2 & 32.3 & 2.1 & 28.3 & 344.7 & 48.3 & $>400$ & 0.0 & 372.3 & & & & & \\
\hline 3 & 9.9 & 1.5 & 17.3 & 4.0 & 13.6 & 210.7 & 164.3 & $>400$ & 0.0 & $>305.3$ & & & & & \\
\hline 4 & 8.8 & 0.4 & 21.3 & 1.5 & 15.1 & 70.7 & 6.4 & 190.3 & 181.6 & 130.5 & & & & & \\
\hline 5 & 7.7 & 1.7 & 8.0 & 1.1 & 7.8 & 70.7 & 7.6 & 69.0 & 35.5 & 69.8 & & & & & \\
\hline 6 & 18.4 & 3.2 & 21.0 & 3.6 & 19.7 & $>400$ & 0.0 & $>400$ & 0.0 & $>400$ & 41.7 & 3.5 & 44.7 & 25.9 & 43.2 \\
\hline 7 & 7.6 & 0.3 & 9.0 & 1.3 & 8.3 & 140.0 & 25.5 & 107.3 & 6.8 & 123.7 & & & & & \\
\hline 8 & 10.2 & 0.1 & 17.7 & 3.5 & 14.0 & $>400$ & 0.0 & 383.7 & 15.2 & $>391.8$ & 80.8 & 1.0 & 18.0 & 2.0 & 49.4 \\
\hline 9 & 24.7 & 0.6 & 29.7 & 2.5 & 27.2 & 205.3 & 75.8 & 192.7 & 14.5 & 199.0 & & & & & \\
\hline 10 & 16.5 & 5.3 & 16.6 & 6.0 & 16.5 & $>400$ & 0.0 & $>400$ & 0.0 & $>400$ & 16.3 & 2.5 & 20.3 & 7.5 & 18.3 \\
\hline 11 & 23.7 & 2.3 & 27.3 & 5.8 & 25.5 & 138.7 & 49.7 & 207.3 & 32.8 & 173.0 & & & & & \\
\hline 12 & 5.1 & 3.5 & 4.5 & 3.5 & 4.8 & 33.0 & 6.6 & 306.7 & 161.7 & 169.8 & & & & & \\
\hline 13 & 7.6 & 3.4 & 13.7 & 3.1 & 10.7 & 85.3 & 6.4 & 92.0 & 28.8 & 88.7 & & & & & \\
\hline 14 & 24.2 & 0.4 & 27.0 & 3.6 & 25.6 & 143.3 & 78.5 & 172.7 & 38.5 & 158.0 & & & & & \\
\hline 15 & 3.2 & 0.5 & 11.3 & 0.6 & 7.3 & $>400$ & 0.0 & $>400$ & 0.0 & $>400$ & 3.8 & 1.3 & 3.3 & 0.3 & 3.6 \\
\hline 16 & 7.2 & 2.1 & 16.0 & 2.6 & 11.6 & $>400$ & 0.0 & 116.0 & 23.4 & $>258.0$ & 23.9 & 1.1 & 25.0 & 13.1 & 24.5 \\
\hline 17 & 254.7 & 186.0 & $>400$ & 0.0 & $>327$ & $>400$ & 0.0 & $>400$ & 0.0 & $>400$ & & & & & \\
\hline DXR & 0.40 & 0.08 & 0.21 & 0.03 & 0.31 & $>10$ & 0.00 & $>10$ & 0.00 & $>10$ & 0.27 & 0.15 & 0.51 & 0.08 & 0.39 \\
\hline $5-\mathrm{FU}$ & 76.3 & 31.9 & $>1000$ & 0.0 & $>538$ & $>1000$ & 0.0 & $>1000$ & 0.0 & $>1000$ & 44.7 & 25.1 & 14.5 & 2.2 & 29.6 \\
\hline
\end{tabular}

HGF, human gingival fibroblast; HPC, human pulp cells; HPLF, human periodontal ligament fibroblast; Ca9-22 (derived from gingival tissue), HSC-2, HSC-3 and HSC-4 (derived from tongue), oral squamous cell carcinoma cell lines; $\mathrm{CC}_{50}, 50 \%$ cytotoxic concentration; DXR, doxorubicin; 5-FU, 5-fluorouracil.

Calculation of PSE. Potency-selectivity expression (PSE) was calculated by the following equation: $\mathrm{PSE}=\mathrm{TS} / \mathrm{meanCC}_{50}$ against tumor cells $(\mathrm{B}) \times 100(23)$, that is, $\left(\mathrm{D} / \mathrm{B}^{2}\right) \times 100(\mathrm{HGF}+\mathrm{HPC} v s$. Ca9$22+\mathrm{HSC}-2)$ and $\left(\mathrm{E}^{-\mathrm{B}^{2}}\right) \times 100(\mathrm{HOK}+\mathrm{HGEP}$ vs. Ca9-22+HSC-2) (Table II).

Estimation of $\mathrm{CC}_{50}$ values. Original data contain the sign of inequality, such as ">". For the convenience of analysis, these values were changed into forms suitable for arithmetic calculation. Since " $>400$ " is equal to "from 400 to $\infty$ ", we calculated the harmonic mean as follows: $1 /[$ average $(1 / 400,1 / \infty)]=800$. Since the $\mathrm{CC}_{50}$ values had a distribution pattern close to a logarithmic normal distribution, we used the $\mathrm{pCC}_{50}$ (i.e. the $-\log \mathrm{CC}_{50}$ ) for the comparison of the cytotoxicity between the compounds. The mean $\mathrm{pCC}_{50}$ values for normal cells and tumor cell lines were defined as $\mathrm{N}$ and $\mathrm{T}$, respectively (24).

Calculation of chemical descriptors. Each chemical structure was optimized by the LowModeMD method (25), a suitable search method for minimum energy conformers of flexible molecules, with Merck Molecular Force Field (MMFF94x) in Molecular Operating Environment (MOE) version 2014.09 (Chemical Computing Group Inc., Quebec, Canada). We used the software MOE (341 descriptors), Dragon 7.0 (Kode srl., Pisa, Italy) (2783 descriptors) and 10 descriptors (that relate the location of substituent groups and types) to calculate descriptors. The significant descriptors used were:

(a) RDF095i (Radial Distribution Function - 095/weighted by ionization potential), RDF095u (Radial Distribution Function 095/unweighted) and RDF095e (Radial Distribution Function 095/weighted by Sanderson electronegativity) (26);

(b) Vsurf_IW6 (Hydrophilic interaction-energy moment 6), Vsurf_ID7 (Hydrophobic interaction-energy moment 7), Vsurf_ID1 (Hydrophobic interaction-energy moment 1) and Vsurf_HB7 (Hbond donor capacity 7) that are similar to the VolSurf descriptors (27) and depend on the structure connectivity and conformation;

(c) Mor03v (signal 03/weighted by van der Waals volume), Mor03m (signal 03/weighted by mass), Mor09m (signal 09/weighted by mass), Mor03p (signal 03/weighted by polarizability) and Mor25v (signal 25/weighted by van der Waals volume) that are 3D-MoRSE (3D-Molecule Representation of Structures based on Electron diffraction) descriptors (28);

(d) G1u (1st component symmetry directional WHIM index/unweighted encoding molecular symmetry that extracts the global symmetry information) (29);

(e) $R 3 m+(R$ maximal autocorrelation of lag $3 /$ weighted by mass) that reflects three-dimensional structure and molecular volume (30); and (f) SpMAD_AEA(dm) (Spectral mean absolute deviation from augmented edge adjacency matrix weighted by dipole moment edge adjacency indices) (31). 
Table II. Tumor-specificity and PSE values of seventeen 3benzylidenechromanones and anticancer drugs, determined with the data of Table I. Each value represents the mean of triplicate determinations.

\begin{tabular}{|c|c|c|c|c|c|}
\hline \multirow[b]{2}{*}{ Normal cells: } & \multicolumn{3}{|c|}{ TS } & \multicolumn{2}{|c|}{ PSE } \\
\hline & & $\begin{array}{l}\text { Epi } \\
v s .\end{array}$ & $\begin{array}{l}\text { Epi } \\
v s .\end{array}$ & $\begin{array}{l}\text { Epi } \\
v s .\end{array}$ & $\begin{array}{l}\text { Epi } \\
v s .\end{array}$ \\
\hline \multirow[t]{2}{*}{ Tumor cells: } & & Mes & Epi & Mes & Epi \\
\hline & $(\mathrm{D} / \mathrm{B})$ & $(\mathrm{C} / \mathrm{A})$ & $(\mathrm{E} / \mathrm{B})$ & $\left(\mathrm{D} / \mathrm{B}^{2}\right) \times 100$ & $\left(\mathrm{E} / \mathrm{B}^{2}\right) \times 100$ \\
\hline 1 & 8.1 & 9.9 & & 86 & \\
\hline 2 & 13.2 & 14.3 & & 47 & \\
\hline 3 & $>22.4$ & 21.2 & & $>164$ & \\
\hline 4 & 8.7 & 8.1 & & 58 & \\
\hline 5 & 8.9 & 9.2 & & 114 & \\
\hline 6 & $>20.3$ & $>21.7$ & 2.2 & $>103$ & 11 \\
\hline 7 & 14.9 & 18.4 & & 180 & \\
\hline 8 & $>28.1$ & $>39.1$ & 3.5 & $>201$ & 25 \\
\hline 9 & 7.3 & 8.3 & & 27 & \\
\hline 10 & $>24.2$ & $>24.2$ & 1.1 & $>146$ & 6.7 \\
\hline 11 & 6.8 & 5.9 & & 27 & \\
\hline 12 & 35.4 & 6.4 & & 737 & \\
\hline 13 & 8.3 & 11.2 & & 78 & \\
\hline 14 & 6.2 & 5.9 & & 24 & \\
\hline 15 & $>55.2$ & $>126.3$ & 0.5 & $>761$ & 6.8 \\
\hline 16 & $>22.2$ & $>55.6$ & 2.1 & $>191$ & 18 \\
\hline 17 & 1.2 & 1.6 & & $<0.37$ & \\
\hline DXR & $>32.8$ & $>24.8$ & 1.3 & $>10754$ & 421 \\
\hline $5-\mathrm{FU}$ & $><1.9$ & $>13.1$ & $<0.06$ & $<0.35$ & $<0.011$ \\
\hline
\end{tabular}

Epi, epithelial; Mes, mesenchymal; TS, Tumor selectivity index; PSE, potency-selectivity expression; $\mathrm{CC}_{50}, 50 \%$ cytotoxic concentration; DXR, doxorubicin; 5-FU, 5-fluorouracil; A, B, C, D, E are explained in Table I.

Statistical treatment. The relation among cytotoxicity, tumor specificity index, anti-UV activity and chemical descriptors was investigated using simple regression analyses by JMP Pro version 12.2.0 (SAS Institute Inc., Cary, NC, USA). The significance level was set at $p<0.05$.

\section{Results}

Cytotoxicity. A total of seventeen 3-benzylidenechromanones derivatives (Figure 1) generally showed higher cytotoxicity against human oral squamous cell lines (Ca9-22 and HSC2) $\left(\mathrm{CC}_{50}=4.8 \sim 327 \mu \mathrm{M}\right.$, mean $\left.=33.7 \mu \mathrm{M}\right)$ than against human mesenchymal normal oral cells (HGF and HPC) $\left(\mathrm{CC}_{50}=69.8 \sim 400 \mu \mathrm{M}\right.$, mean $\left.=242 \mu \mathrm{M}\right)$ with an averaged tumor-specificity index (TS) of $7.2(=242 / 34)$ (Table I). Among them, compounds $[3,6,8,10,12,15,16]$ showed much higher TS (20.3 55.2), comparable with that of the anticancer drug DXR (32.8). When tumor-selectivity was calculated using cells both derived from the gingival tissue (Ca9-22 vs. HGF), compounds $[\mathbf{6}, \mathbf{8}, \mathbf{1 0}, \mathbf{1 5}, \mathbf{1 6}]$ showed much higher TS (21.7 126.3), exceeding that of DXR (24.8) and 5-FU (13.1). When tumor-selectivity was calculated using cells both derived from the epithelial tissues, compounds $[\mathbf{6}, \mathbf{8}, \mathbf{1 6}]$ showed much reduced tumorselectivity (2.1 3.5), while DXR and 5-FU showed little or no tumor-specificity $(0.06 \sim 1.3)$ due to their cytotoxicity against human keratinocytes (Table II).

In order to identify compounds, which have both good potencies and are selectively toxic to neoplasms, the potency-selectivity expression (PSE) values of the compounds were calculated by the following equation: $\mathrm{PSE}=$ $\left(\mathrm{TS} / \mathrm{CC}_{50}\right) \times 100(23)$. When mesenchymal (HGF and HPC) vs. Ca9-22+HSC-2 were used, DXR showed the highest PSE value (10754), followed by 3-benzylidenechromanones $(0.37 \sim 761$, mean $=173$, two orders lower than DXR) and then 5-FU (0.35) (Table II). When epithelial (HOK and HGEP) vs. Ca9-22+HSC-2 were used, DXR again showed the highest PSE value (421), followed by compounds $[\mathbf{6 , 8}, \mathbf{1 0}$, 15, 16] $(6.7 \sim 25$, mean=14) and then 5-FU (0.011) (Table II).

Computational analysis. Since compound [17] showed very week tumor-specificity (1.2) and PSE (0.37) (Table II), we performed QSAR analysis with compounds [1 16]. More than 3,000 kinds of feature values with or without each functional group were calculated, based on chemical structures.

Cytotoxicity of 3-benzylidenechromanones against human OSCC cell lines (Ca9-22, HSC-2) was correlated with RDF095 (Radial Distribution Function - 095)i (ionization potential) $\left(\mathrm{r}^{2}=0.497, p=0.0023\right), \mathrm{RDF} 095 \mathrm{u}$ (unweighted) $\left(r^{2}=0.442, p=0.0049\right)$, RDF095e (Sanderson electronegativity) $\left(\mathrm{r}^{2}=0.442, p=0.0049\right)$, Hydrophilic integy moment, such as Vsurf_IW6 $\left(\mathrm{r}^{2}=0.401, p=0.0085\right)$, Vsurf_ID7 $\left(\mathrm{r}^{2}=0.381\right.$, $p=0.0108)$ and Vsurf_ID1 ( $\mathrm{r} 2=0.352, p=0.0154)$ (Figure 2).

Cytotoxicity of 3-benzylidenechromanones against mesenchymal normal cells (HGF, HPC) was correlated with Mor03v (van der Waals volume) $\left(\mathrm{r}^{2}=0.505, p=0.002\right)$, Mor03m (mass) $\left(\mathrm{r}^{2}=0.477, p=0.003\right)$, Mor09m (mass) $\left(\mathrm{r}^{2}=0.465, p=0.0036\right), \mathrm{G} 1 \mathrm{u}$ (1st component symmetry directional WHIM index/unweighted) $\left(\mathrm{r}^{2}=0.410, p=0.0075\right)$, Mor03p (polarizability) $\left(\mathrm{r}^{2}=0.408, p=0.0077\right)$ and $\mathrm{R} 3 \mathrm{~m}+$ (mass) $\left(\mathrm{r}^{2}=0.398, p=0.0088\right)$ (Figure 3 ).

Tumor-specificity of 3-benzylidenechromanones was correlated with Mor03m (mass) $\left(\mathrm{r}^{2}=0.607, p=0.0004\right)$, Mor03v (van der Waals volume) $\left(\mathrm{r}^{2}=0.560, p=0.0009\right)$, SpMAD_AEA $(\mathrm{dm})$ (dipole moment edge adjacency indices) $\left(\mathrm{r}^{2}=0.537, p=0.0012\right)$, Vsurf_HB7 (H-bond donor capacity) $\left(\mathrm{r}^{2}=0.502, p=0.0021\right), \mathrm{R} 3 \mathrm{~m}+($ mass $)\left(\mathrm{r}^{2}=0.497, p=0.0023\right)$ and Mor25v (van der Waals volume) $\left(\mathrm{r}^{2}=0.488, p=0.0026\right)$ (Figure 4).

Introduction of hydroxyl group at 3'-position of benzene ring was correlated more significantly with tumor-specificity $(p=0.0051)$, as compared to cytotoxicity against normal cells $(p=0.0217)$ or tumor cells $(p=0.547)$ (Figure 5). 


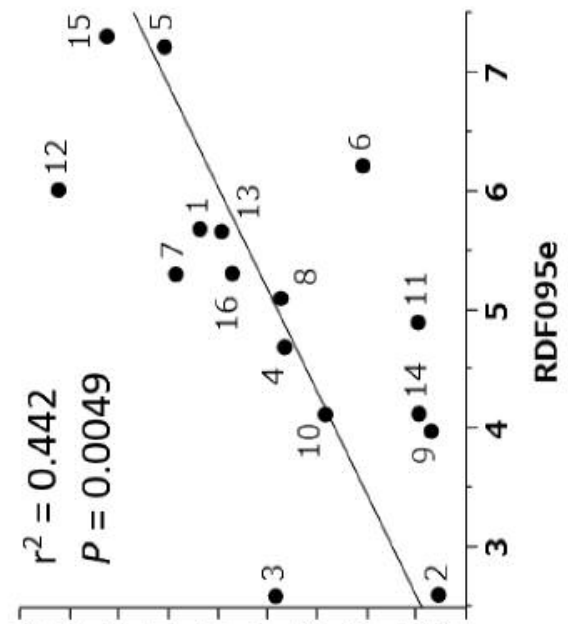

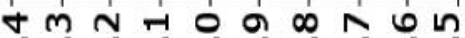

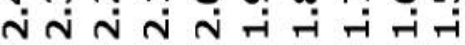

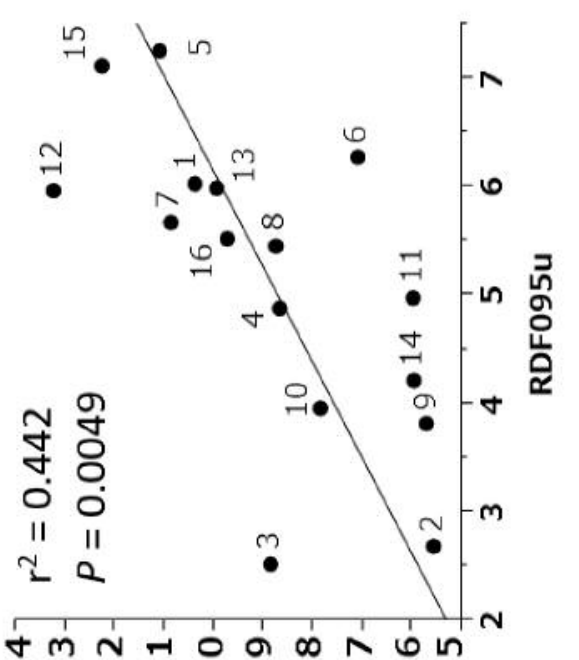

ัง

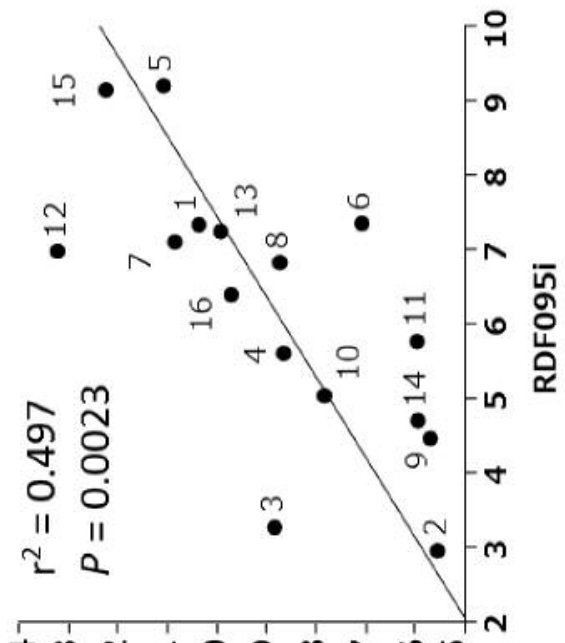

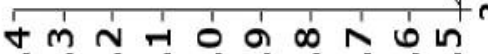

ง $\dot{4}$ ง

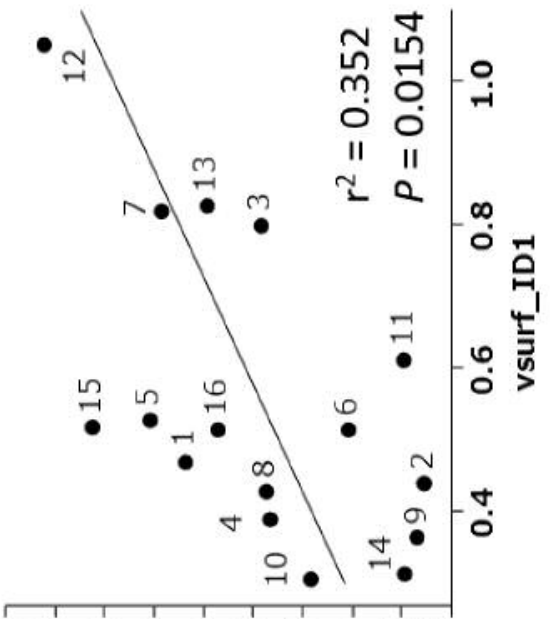

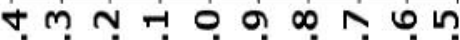

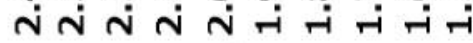

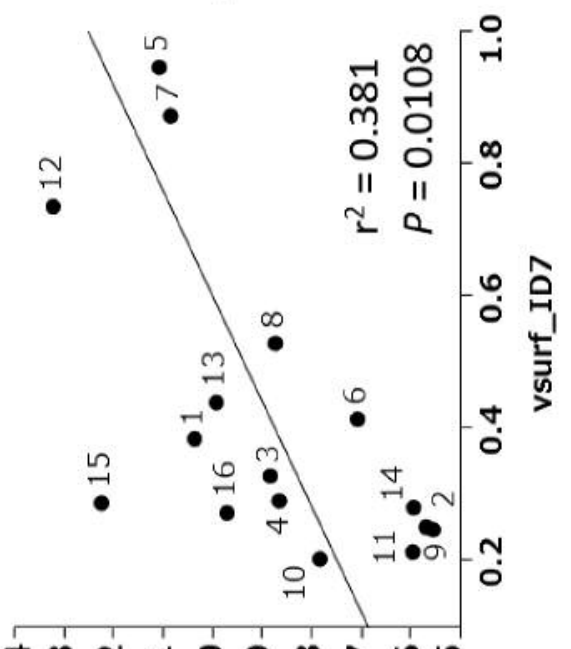

ชัต

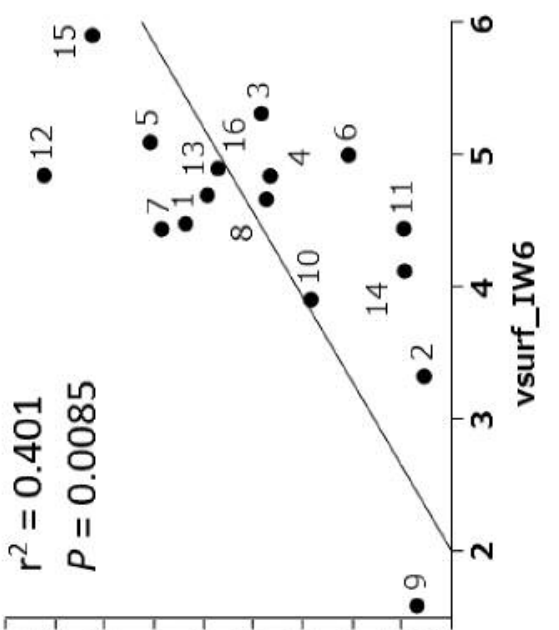

t m n

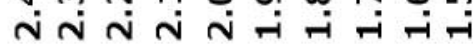



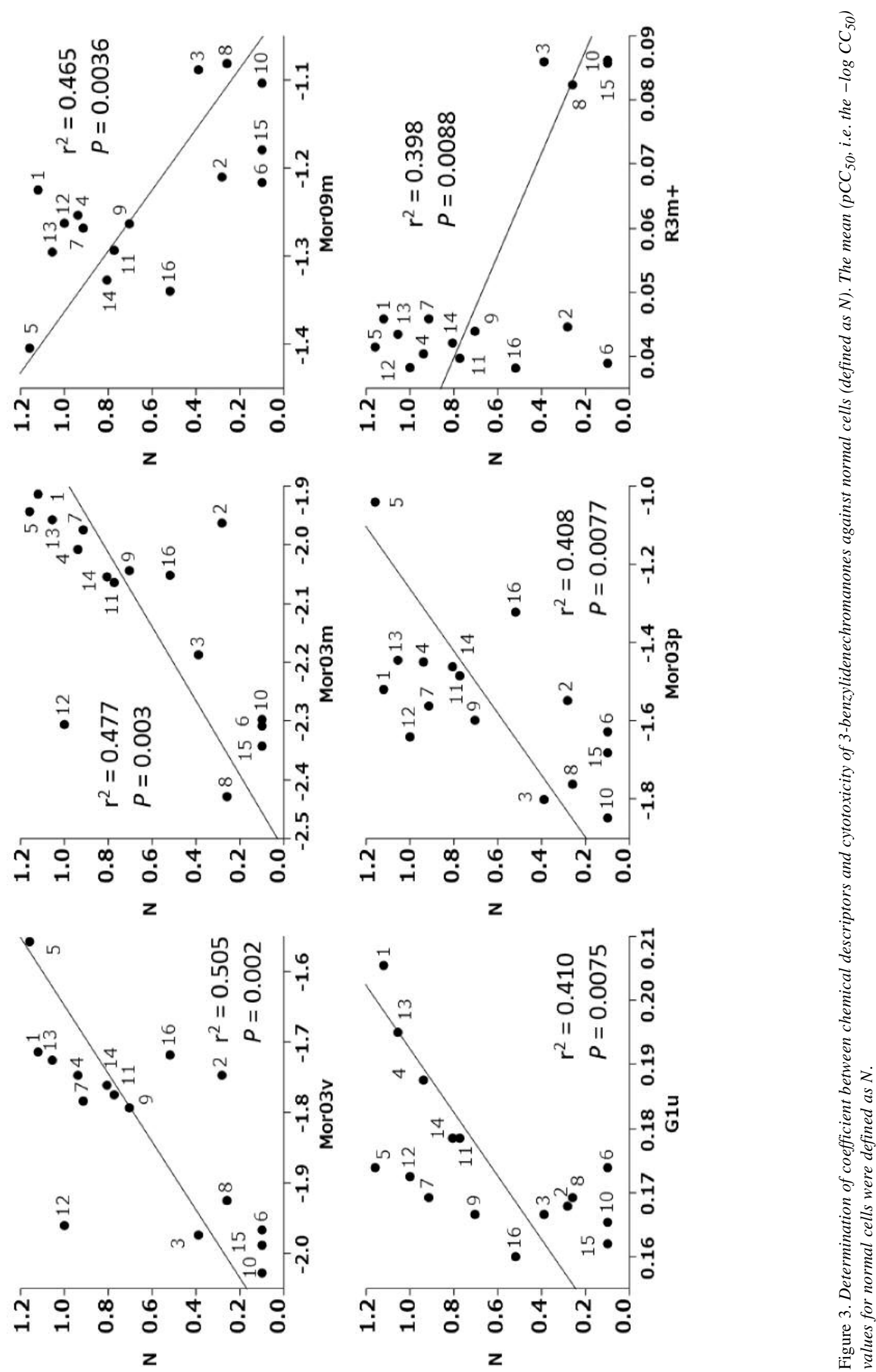

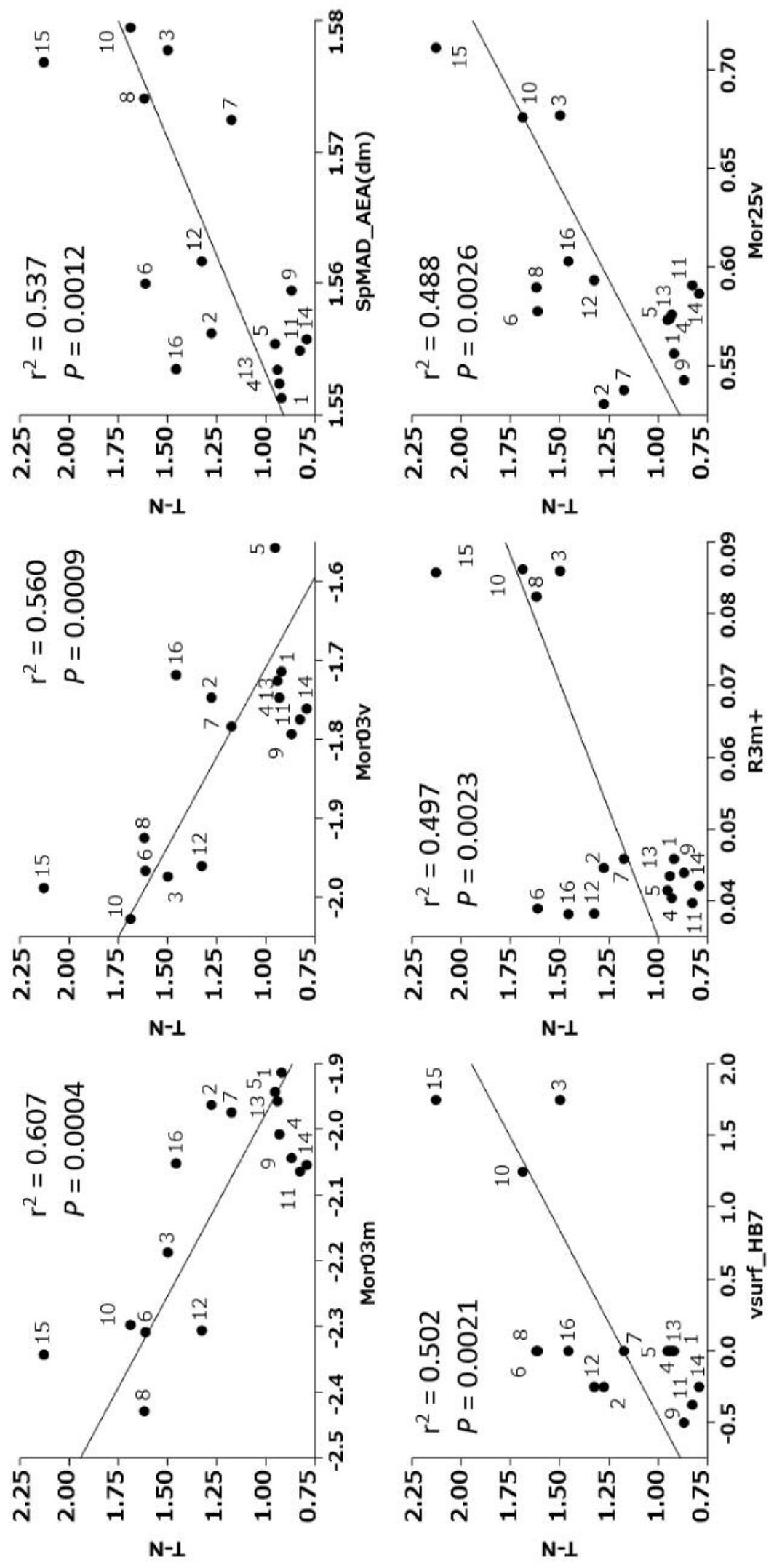


\section{Discussion}

The present study demonstrated that compounds $[\mathbf{3}, \mathbf{1 0}, \mathbf{1 5}]$ with hydroxyl group in the 3'-position of the benzene ring significantly contribute to the tumor-specificity $(p=0.0051)$. Compound [10], also known as sappanone $\mathrm{A}$, has been recently reported to exert its anti-inflammatory activity by activating nuclear factor erythroid 2-related factor (Nrf2)/ heme oxygenase-1 (HO-1) pathway and suppressing the nuclear factor-kB (NF-kB) activation (32). Compound [16] showed antibacterial and antifungal activities (33). Compounds $[\mathbf{9 , 1 1}]$ inhibited the efflux of antimicrobials, such as ethidium bromide from the Mycobacterium smegmatis $\mathrm{mc}^{2}$ 155 , suggesting their possible candidacy as anti- tuberculosis drugs by reducing drug-resistance (10). On the other hand, the anti-cancer study of homoisoflavonoids has been limited, possibly due to the absence of appropriate assay method for tumor-selectivity. We have recently explored a new method by which tumor-selectivity can be estimated (34). Although this system uses two different types of cells, human oral normal mesenchymal cells with human OSCC cell lines, the TS value obtained yielded the clinically expected values, judging from the evidence that most of the anticancer drugs and herbs produced extremely higher TS values $(18,34)$. The use of human oral keratinocytes led to our unexpected finding that OSCC cell lines were very much sensitive to DXR and 5-FU, confirming our recent papers $(35,36)$. This may be a new type of side-effect induced by anticancer drugs. We found that compounds $[6,8,16]$ showed much lower cytotoxicity against human normal keratinocytes as compared with DXR and 5FU (Table II). It is urgent to explore the method by which this type of side-effect can be alleviated.

We also found that the introduction of dimethylamino groups $[\mathbf{6}, \mathbf{1 2}]$ and chloride $[\mathbf{8}]$ in the 4 '-position of benzene ring produced comparable TS values with $[\mathbf{3}, \mathbf{1 0}, \mathbf{1 5}]$. This indicates that molecular shape, size and polarization are useful for the evaluation of tumor-specificity of 3benzylidenechromanone derivatives.

\section{Conflicts of Interest}

The Authors wish to confirm that there are no known conflicts of interest associated with this publication and there has been no significant financial support for this work that could have influenced its outcome.

\section{Acknowledgements}

This work was partially supported by KAKENHI from the Japan Society for the Promotion of Science (JSPS) (15K08111, 16K11519). The annual license of the statistical software, JMP Pro, was supported by the Grant-in-Aid of the oncology specialists promotion program by the Ministry of Education, Culture, Sports, Science and Technology, Japan.
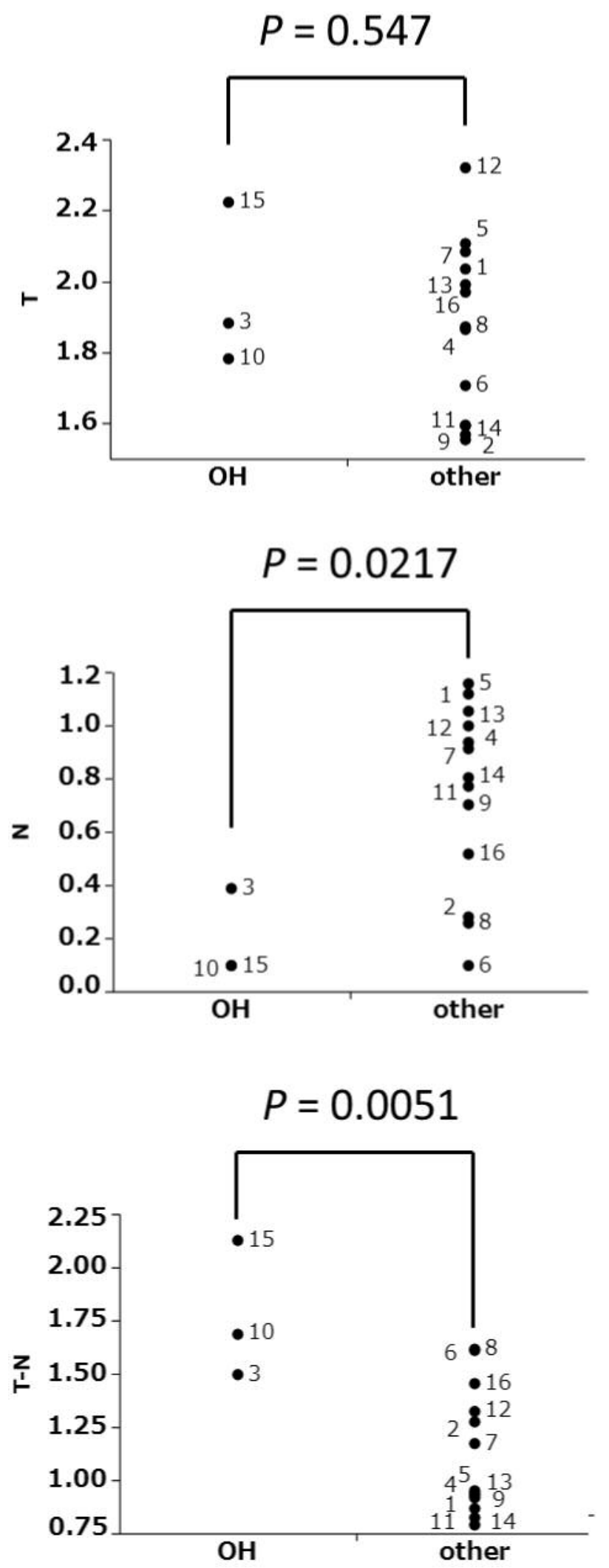

Figure 5. Effect of introduction of hydroxyl group on 3'-position of benzene ring on $T, N$ and $N-T$. 


\section{References}

1 Lin LG, Liu QY and Ye Y: Naturally occurring homoisoflavonoids and their pharmacological activities. Planta Med 80: 1053-1066, 2014.

2 Yan J, Sun LR, Zhou ZY, Chen YC, Zhang WM, Dai HF and Tan JW: Homoisoflavonoids from the medicinal plant Portulaca oleracea. Phytochemistry 80: 37-41, 2012.

3 Siddaiah V, Maheswara M, Venkata Rao C, Venkateswarlu S and Subbaraju GV. Synthesis, structural revision, and antioxidant activities of antimutagenic homoisoflavonoids from Hoffmanosse-ggia intricata. Bioorg Med Chem Letters 17: 1288-1290, 2007.

4 Lin L G, Xie H, Li HL, Tong LJ, Tang CP, Ke CQ, Liu QF, Lin LP, Geng MY, Jiang H, Zhao WM, Ding J and Ye Y: Naturally occurring homoisoflavonoids function as potent protein tyrosine kinase inhibitors by c-Src-based high-throughput screening. J Med Chem 51: 4419-4429, 2008.

5 Famuyiwa SO, Ntumy AN, Andrae-Marobela K and Yeboah SO: A new homoisoflavonoid and the bioactivities of some selected homoisoflavonoids from the inter-bulb surfaces of Scilla nervosa subsp. Rigidifolia. South African J Botany 88: 17-22, 2013.

6 Emami S and Ghanbarimasir Z: Recent advances of chroman-4one derivatives: synthetic approaches and bioactivities. Eur J Med Chem 93: 539-563, 2015.

7 Noushini S, Alipour E, Emami S, Safavi M, Ardestani SK, Gohari AR, Shafiee A and Foroumadi A: Synthesis and cytotoxic properties of novel (E)-3-benzylidene-7-methoxychroman-4-one derivatives. Daru 21: 31, 2013.

8 Perjési P, Das U, De Clercq E, Balzarini J, Kawase M, Sakagami H, Stables JP, Lorand T, Rozmer Z and Dimmock JR: Design, synthesis and antiproliferative activity of some 3-benzylidene2,3-dihydro-1-benzopyran-4-ones which display selective toxicity for malignant cells. Eur J Med Chem 43: 839-845, 2008

9 Letafat B, Shakeri R, Emami S, Noushini S, Mohammadhosseini N, Shirkavand N, Kabudanian Ardestani S, Safavi M, Samadizadeh M, Letafat A, Sha Ee A and Foroumadi AI: Synthesis and in vitro cytotoxic activity of novel chalcone-like agents. J Basic Med Sci 16: 1155-1162, 2013.

10 Roy SK, Kumari N, Gupta S, Pahwa S, Nandanwar H and Jachak SM: 7-Hydroxy-(E)-3-phenylmethylene-chroman-4-one analogues as efflux pump inhibitors against Mycobacterium smegmatis mc ${ }^{2}$ 155. Eur J Med Chem 66: 499-507, 2013.

11 Siddaiah V, Rao CV, Venkateswarlu S, Krishnaraju A V and Subbaraju GV: Synthesis, stereochemical assignments, and biological activities of homoisoflavonoids. Bioorg Med Chem 14: 2545-2551, 2006.

12 Foroumadi A, Samzadeh-Kermani A, Emami S, Dehghan G, Sorkhi M, Arabsorkhi F, Heidari MR, Abdollahi M and Shafiee A: Synthesis and antioxidant properties of substituted 3benzylidene-7-alkoxychroman-4-ones. Bioorg Med Chem Lett 17: 6764-6769, 2007.

13 Jacquot Y, Byrne C, Xicluna A and Leclercq G: Synthesis, structure, and estrogenic activity of 2- and 3-substituted 2,3dihydro-4H-1-benzopyran-4-ones. Med Chem Res 22: 681-691, 2013.

14 Desideri N, Bolasco A, Fioravanti R, Monaco LP, Orallo F, Yáñez M, Ortuso $F$ and Alcaro S: Homoisoflavonoids: natural scaffolds with potent and selective monoamine oxidase-B inhibition properties. J Med Chem 54: 2155-2164, 2011.
15 Gan C, Zhao Z, Nan DD, Yin B and Hu JE: Homoisoflavonoids as potential imaging agents for $\beta$-amyloid plaques in Alzheimer's disease. J Med Chem 76: 125-131, 2014.

16 Conti C, Proietti Monaco L and Desideri N: Design, synthesis and in vitro evaluation of novel chroman-4-one, chroman, and $2 \mathrm{H}$-chromene derivatives as human rhinovirus capsid-binding inhibitors. Bioorg Med Chem 19: 7357-7364, 2011.

17 Conti C, Proietti Monaco L and Desideri N: Synthesis and antirhinovirus activity of novel 3-[2-(pyridinyl)vinyl]substituted $2 H$-chromenes and $-4 H$-chromen-4-ones. Bioorg Med Chem 22: 1201-1207, 2014.

18 Suzuki R, Matsuo S, Sakagami H, Okada Y and Shirataki Y: Search of new cytotoxic crude materials against human oral squamous cell carcinoma using ${ }_{1} \mathrm{H}$ NMR-based metabolomics. Anticancer Res 34: 4117-4120, 2014.

19 Takao K, Yamashita M, Yashiro A and Sugita Y: Synthesis and biological evaluation of 3-benzylidene-4-chromanone derivatives as free radical scavengers and $\alpha$-glucosidase inhibitors. Chem Pharm Bull 64: 1203-1207, 2016.

20 Siddaiah V, Rao CV, Venkateswarlu S, Krishnaraju AV and Subbaraju GV: Synthesis, stereochemical assignments, and biological activities of homoisoflavonoids. Bioorg Med Chem 14: 2545-2551, 2006.

21 Kantoh K, Ono M, Nakamura Y, Nakamura Y, Hashimoto K, Sakagami H and Wakabayashi H: Hormetic and anti-radiation effects of tropolone-related compounds. In Vivo 24: 843-852, 2010.

22 Horikoshi M, Kimura Y, Nagura H, Ono T and Ito H: A new human cell line derived from human carcinoma of the gingiva. I. Its establishment and morphological studies. Jpn J Oral Maxillofac Surg 20: 100-106, 1974 (in Japanese).

23 Das S, Das U, Sakagami H, Umemura N, Iwamoto S, Matsuta T, Kawase M, Molnar J, Serly J, Gorecki DKJ and Dimmock JR: Dimeric 3,5-bis(benzylidene)-4-piperidones: A novel cluster of tumour-selective cytotoxins possessing multidrug-resistant properties. Eur J Med Chem 51: 193-199, 2012.

24 Ohno H, Araho D, Uesawa Y, Kagaya H, Ishihara M, Sakagami $\mathrm{H}$ and Yamamoto $\mathrm{M}$ : Evaluation of cytotoxicity and tumor specificity of licorice flavonoids based on chemical structures. Anticancer Res 33: 3061-3068, 2013.

25 Hemmer MC, Dteinauer V and Gasteigeer J: Deriving the 3D structure of organic molecules from their infrared spectra. Vibrat Dpect 19: 151-164, 1999.

26 Cruciani G, Crivori P, Carrupt P-A and Testa B: Molecular fields in quantitative structure-permeation relationships: the VolSurf approach. J Mol Struct (Theochem) 503: 17-30, 2000.

27 Schuur $\mathrm{J}$ and Gasteiger $\mathrm{J}$ : Infrared spectra simulation of substituted benzene derivatives on the basis of a 3D structure representation. Anal Chem 69: 2393-2405, 1997.

28 Todeschini R and Gramatica P: The WHIM THEORY: New 3Dmolecular descriptors for QSAR in environmental modeling. SAR QSAR Environ Res 7: 89-115, 1997.

29 Todeschini R, Lasagni $M$ and Marengo E: New molecular descriptors for 2D and 3D structures. J Chemom 8(4): 263-272, 1994.

30 Consonni V, Todeschini R, Pavan M, Gramatica P: Structure/response correlations and similarity/diversity analysis by GETAWAY descriptors. 2. Application of the novel 3D molecular descriptors to QSAR/QSPR studies. J Chem Inf Comput Sci 42(3): 693-705, 2002. 
31 Estrada E: Edge adjacency relationships and a novel topological index related to molecular volume. J Chem Inf Comput Sci, 35(1): 31-33, 1995.

32 Lee S, Choi SY, Choo YY, Kim O, Tran PT, Dao CT, Min BS and Lee JH: Sappanone A exhibits anti-inflammatory effects via modulation of Nrf2 and NF-kB. Int Immunopharmacol 28(1): 328-336, 2015.

33 Das B, Thirupathi P, Ravikanth B, Aravind Kumar R, Sarma AV and Basha SJ: Isolation, synthesis, and bioactivity of homoisoflavonoids from Caesalpinia pulcherrima. Chem Pharm Bull (Tokyo) 57(10): 1139-1141, 2009.

34 Sakagami H: Biological activities and possible dental application of three major groups of polyphenols. J Pharmacol Sci 126: 92$106,2014$.
35 Sakagami H, Shimada C, Kanda Y, Amano O, Sugimoto M, Ota S, Soga T, Tomita M, Sato A, Tanuma S, Takao K and Sugita Y: Effects of 3-styrylchromones on metabolic profiles and cell death in oral squamous cell carcinoma cells. Toxocol Rep 2: 1281-1290, 2015.

36 Sakagami H, Uesawa Y, Ishihara M, Kagaya H, Kanamoto T, Terakubo S, Nakashima H, Takao K and Sugita Y. Quantitative structure-cytotoxicity relationship of oleoylamides. Anticancer Res 35: 5341-5355, 2015.

Received June 23, 2016

Revised July 8, 2016

Accepted July 11, 2016 